\title{
A Study on the Enhancement of the International Regulatory Regime for Sea Transport of Radioactive Material through Improving the INF Code
}

\author{
Ji-Hoon Suk* \\ * Statutory Service Team, Korean Register of Shipping, Busan 618-814, the Republic. of Korea
}

\begin{abstract}
The transport of radioactive material by sea is strictly governed by the international regulatory regime which is established by both IAEA and IMO. Nonetheless, although the current regime is well established, due to catastrophic results of potential accident, it is essential to keep identifying areas where further enhancement is necessary. This paper reviews the current regulatory regime governing sea transport, such as IAEA Regulations, IMDG Code and INF Code. Then, specific requirements of the INF Code are analyzed for the purpose of identifying areas where improvement is necessary from the perspective of ships. Through this analysis, this paper identifies areas to be improved and proposes to improve the INF Code which can supplement the current regulatory regime for sea transport of radioactive material.
\end{abstract}

Key words : INF Code, IMDG Code, sea transport, radioactive materials, IMO, dangerous goods

\section{Introduction}

Nuclear power has been playing an important role in meeting the world's increasing demand for energy. Especially, the nuclear power attracted attentions of the world in 1970s oil crisis as an alternative source of energy. Nonetheless, while recognizing its necessity, the potential risk involved in nuclear power is very much high as shown in the case of Chernobyl nuclear accident in 26 April 1986. After the Chernobyl accident, International Atomic Energy Agency(IAEA), which was originally established to promote nuclear energy, turned its priority to the enhancement of nuclear safety(Kim, 2009). The measures to enhance the nuclear safety are based on one principle of the international law, which is so called "no harm rule". ${ }^{1)}$ Based on this principle, those measures have been taken by the international community including IAEA from various aspects such as radiation safety, the safety of radioactive waste safety, the safe transport of radioactive material, etc. Among them, the safety of transport is gaining an attention due to potential risks to harm others and its worldwide characteristics. For these reasons, the transport of radioactive material is strictly governed by the international regulatory regime. Especially, the regulatory regime for sea transport of radioactive material is governed both by IAEA and International Maritime Organization (IMO). This paper focuses on the regulatory regime for sea transport of radioactive material, especially INF cargo ${ }^{2)}$, for the purpose of its enhancement through improving requirements from the perspective of ships. For this purpose, the current regulatory regime governing sea transport is reviewed. Then, the analysis is made specifically regarding requirements of the "International Code of the Safety Carriage of Packaged Irradiated Nuclear Fuel, Plutonium and High-Level Radioactive Wastes on Board Ships", hereinafter referred to as the "INF Code". Through this analysis, areas to be improved are identified and a proposal to improve the INF Code is made. As the areas to be improved, first of all, this study deals with the current survey and certification scheme under the INF Code for the purpose of enhancing the current scheme. Then, this study proposes to update references related to SOLAS requirements in the INF Code for its proper application. Lastly, this study emphasizes the necessity to develop management and training guidelines specifically for ships carrying INF cargo.

* sukjh@krs.co.kr 070)8799-8304

1) No harm rule is based on an ancient Roman law maxim "sic utere tuo non alienum laedus" which means "use your property in such a way that you do not damage others". This maxim was supported in several legal cases such as Trail Smelter Case, Corfu Channel Case, Lake Lanoux Arbitration, etc.(Roe, 2003; New International Environmental Law, Seoul: Bobmunsa; Kim, 2010), International Environmental Law, Seoul: Hongmoonsa). This no harm rule can also be found in Article 194.2 of the United Nations Convention on the Law of the Sea(UNCLOS).

2) According to the definition in 1.1.1.3 of Chapter 1 of the INF Code, "INF cargo" means packaged irradiated nuclear fuel, plutonium and high-level radioactive wastes carried as cargo in accordance with class 7 of the IMDG Code. 


\section{International Regulatory Framework for Sea Transport of Radioactive Materials}

Both organizations of IAEA and IMO are regulating various aspects related to sea transport of radioactive material to ensure the safety of people, property and environment. In this chapter, the current international regulatory regime for sea transport of radioactive material governed by IAEA and IMO is reviewed in detail.

\subsection{IAEA Regulations}

IAEA is the competent international organization in connection with the establishment or adoption of standards of safety for protection of health and minimization of danger to life and property ${ }^{3)}$. With this mandate, IAEA establishes various safety standards which cover nuclear safety, radiation safety, transport safety, waste safety, etc. With regard to transport of radioactive materials, the governing regulations are "IAEA Regulations for the Safe Transport of Radioactive Material" which are also supplemented by a hierarchy of Safety Guides ${ }^{4)}$ including "Advisory Material for the IAEA Regulations for the Safe Transport of Radioactive Material", "Planning and Preparing for Emergency Response to Transport Accidents Involving Radioactive Material", "Compliance Assurance for the Safe Transport of Radioactive Material", and "Quality Assurance for the Safe Transport of Radioactive Material"(IAEA, 2005). The Regulations are applicable to the national and international transport of radioactive material by all modes of transport including sea transport. The objective of the Regulations is the protection of persons, property and the environment from the effects of radiation during the transport of radioactive material, by ensuring the safety primarily through the package whatever mode of transport(IAEA, 2005). More specifically, the requirements include content limits for packages and conveyances ${ }^{5)}$, performance standards for package design, the operation of packages, the maintenance of packagings, etc., covering both normal and potential accident conditions of transport.

\subsection{IMDG Code}

Chapter VII of the International Convention for the
Safety of Life at Sea 1974, hereinafter referred to as "SOLAS", is dedicated to dealing with the safe carriage of dangerous goods. Especially, regulation 3 requires that the carriage of dangerous goods in packaged form shall be in compliance with the relevant provisions of the "International Maritime Dangerous Goods Code", hereinafter referred to as the "IMDG Code". The initiative to develop the IMDG Code was taken from the 1960 SOLAS Conference which recommended that, for the purpose of supplementing the relevant provisions in the 1960 SOLAS, a uniform international code should be developed for the transport of dangerous goods by sea. As a result, Resolution 56 was adopted recommending that the proposed code should cover such matters as packing, container stowage, with special reference to the segregation of incompatible substances. Through extensive discussions in close $\mathrm{Co}^{-}$operation with the United Nations Committee of Experts on the Transport of Dangerous Goods, IMO Working Group on the Carriage of Dangerous Goods prepared the IMDG Code which was consequently adopted by IMO Assembly at its 4th session in 1965(IMO, 1996).

Since its adoption in 1965, the IMDG Code has undergone various amendments to keep step with technological and regulatory developments. Especially, with regard to radioactive materials, the IMDG Code, since Amendment 30 in 2001, has reproduced the IAEA Regulations for the Safe Transport of Radioactive Material and has been consistent with the IAEA Regulations(WNTI, 2006). In addition, after the IMDG Code was reformatted into two volumes in 2001 with a Supplement, the INF Code was included in the Supplement.

In 2002, Maritime Safety Committee(MSC) at its 75th session adopted amendments to Chapter VII of SOLAS by resolution MSC.123(75), making the IMDG Code mandatory from 1 January 2004.

\subsection{INF Code}

The requirements for radioactive materials in the IMDG Code are based on the IAEA Regulations and, as previously mentioned, focus on such matters as packing, container stowage, with special reference to the segregation of incompatible substances. In other words, the

3) Statute of the IAEA, Article III, paragraph 6.

4) IAEA Safety Standard Series have three categories which are Safety Fundamentals, Safety Requirements and Safety Guides.

5) According to the definition in paragraph 217 of Regulations for the Safe Transport of Radioactive Material, "conveyance" shall mean

(a) for transport by road or rail: any vehicle,

(b) for transport by water: any vessel, or any hold, compartment, or defined deck area of a vessel, and

(c) for transport by air: any aircraft 
requirements are more cargo- $^{-}$specific. Since there was no ship-specific requirements until 1980s, concerns were continuously raised with regard to the necessity to provide a mandatory application of the agreed international standards specifically for INF ships. Consequently, through extensive discussions, the recommendatory INF Code was firstly developed and adopted in 1993 and then the mandatory INF Code in 1999. The background to the development of the INF Code is introduced in detail in the next chapter.

The mandatory INF Code, which is effective from 1 January 2001, applies to all ships regardless of the date of construction and size, engaged in the carriage of INF cargo. In the next chapter, specific features of the Code are dealt with for the purpose of identifying areas to be improved in the current regulatory regime from the perspective of ships.

\section{Character of INF Code}

\subsection{Background to the Development of the INF Code}

With regard to the design and equipment of ships carrying dangerous goods, the requirements for that purpose were firstly introduced in 1981 by means of regulation 54 of Chapter II-2 of SOLAS. However, no special design and equipment requirements for radioactive materials, which is class 7 , were included in regulation 54 . With regard to lack of these requirements related to class 7, Italy raised concerns at MSC 52 in 1985 that non-purpose-built ships could engage in unregulated transport of radioactive materials without sufficient consideration having been taken into account the appropriateness of fire protection or damage stability. In 1990, in response to a request that the maximum quantities of radioactive materials should be defined in order to be allowed for carriage on non-purpose-built ships, the requirements for three classes of ships according to the aggregated quantity of radioactive materials to be carried were drawn up by IMO(Wonham, et al., 2000). In the case where radioactive materials are transported in large quantities, IMO had an opinion that there would be the need for specific ship design or fire protection requirements. However, IAEA had a different view from IMO. The 8th session of the IAEA Standing Advisory Group on the Safe Transport of Radioactive Material was of the opinion that there would be no need for specific ship design or fire protection requirements when transporting them in large quantities(Booker, 2003). Taking into consideration public concern for the safety of sea transport of radioactive material and the opinion by the IAEA Standing Advisory Group, the IAEA Director General, by letter of 1992-01-21, had proposed the IMO Secretary-General to form a joint IAEA/IMO coordinating group for the purposes of ensuring that the decision process in both organizations is on an informed and scientific basis. This led to the establishment of the Joint IAEA/IMO Working Group(IAEA, 2001). The Joint Working Group met two times in 1992 and 1993 for discussion and drew up the draft Code for the Safe Carriage of Irradiated Nuclear Fuel, Plutonium and High-Level Radioactive Wastes in Flasks on Board Ships which was adopted as a recommendatory code by IMO resolution A.748(18).

\subsection{Recommendatory INF Code (Resolution A.748(18))}

The INF Code adopted by Resolution A.748(18) applies to new and existing ships, regardless of size, carrying irradiated fuel, plutonium and high-level radioactive wastes in flasks(IMO, 1993). However, the Code is recommendatory in nature and, through its adoption, Governments were urged to implement it at the earliest possible opportunity.

In 1995, IMO Assembly requested MSC and the Marine Environment Protection Committee(MEPC), in consultation with IAEA and UNEP, to consider such matters as adequacy of exiting emergency response arrangements, notification to the coastal States concerned in the event of an accident or any other event which could endanger the safety of the ship, etc.(IMO, 1995). As a follow-up action, draft amendments to the recommendatory INF Code were drawn up by MSC 68 and MEPC 39 regarding shipboard emergency plan and notification in the event of an incident involving INF Code materials, and subsequently adopted by IMO Assembly at its 20th session(IMO, 1997a). In accordance with these amendments, every ship carrying INF Code materials, after 1 July 1998, should carry a shipboard emergency plan which should be approved by the flag Administration. In addition, IMO Assembly adopted specific guidelines for developing shipboard emergency plans for ships carrying materials subject to the INF Code, as Resolution A.854(20), in order to assist shipowners in preparing the plans and assist in responding to shipboard emergencies involving INF Code materials and in providing 
information to authorities involved in handling INF Code materials related incidents(IMO, 1997b). Furthermore, through these amendments, the reporting requirements of regulation VII/7-1 of SOLAS were extended to the loss or likely loss of the INF Code cargo overboard as well as to any incident involving a release or probable release of INF Code material.

\subsection{Mandatory INF Code (Resolution MSC.88(71))}

After the adoption of the recommendatory INF Code, there was ongoing pressure that the additional measures should be taken to secure the safe carriage of INF Code material. This pressure led IMO to adopt resolution A.790(19) for the further review of the Code. ${ }^{6)}$ Moreover, there was a strong demand that, as an additional safety measure, the recommendatory INF Code should be made mandatory. Since then, the necessity to provide the mandatory scheme for ensuring the safe carriage of INF Code material had been continually recognized and finally MSC 71 adopted the completely revised INF Code by resolution MSC.88(71) (IMO, 1999b). This revised Code was, in turn, made mandatory through amendments to SOLAS Chapter VII where, by resolution MSC.87(71), Part D titled "Special Requirements for the Carriage of Packaged Irradiated Nuclear Fuel, Plutonium and High-Level Radioactive Wastes on Board Ships" was newly added to Chapter VII and its regulation 16 specifically requires that a ship carrying INF cargo shall comply with the INF Code in addition to any other applicable requirements of the present regulations(IMO, 1999a).

\subsection{Specific requirements in the INF Code}

Since this paper focuses on enhancement of the current regulatory regime regarding the safe carriage of INF cargo from the perspective of a ship, it is necessary to deal with requirements in the mandatory INF Code more specifically. The mandatory INF Code is referred to as the INF Code hereinafter.

1) Survey and certification of ships carrying INF cargo

The recommendatory INF Code divides ships into three classes, that is, Class INF 1, Class INF 2 and Class INF 3, depending on the total radioactive quantity which is carried on board. The same applies to the INF Code. INF cargo required to be carried on Class INF 3 ships shall not be allowed on passenger ships in accordance with section 1.2.3 of the INF Code and may only be carried on purpose-built INF cargo ships whereas INF cargo required to be carried on Class INF 1 and Class INF 2 ships can be carried on conventional cargo ships and passenger ships(WNTI, 2006). According to section 1.3 of the Code, all these classes of INF ships are subject to survey and certification. This measure is newly introduced in the INF Code for the purpose of ensuring that the structure, equipment, arrangement, material, etc comply with the requirements of the Code.

Especially, regulation VII/16 of SOLAS stipulates that a ship carrying INF cargo shall be surveyed and certified as provided in the INF Code. In addition, a ship holding a certificate issued under the Code shall be subject to port state controls and, for this purpose, such certificate shall be treated as a certificate issued under regulation $\mathrm{I} / 12$ or I/13 of SOLAS. In the same context, the INF Code provides in section 1.3.3 that a ship certified for the carried of INF cargo shall be subject to inspections and surveys under the applicable provisions of Chapter I of SOLAS.

The appendix of the INF Code provides a form of International Certificate of Fitness for the Carriage of INF Cargo, hereinafter referred to as the "Certificate of Fitness". With regard to the language to be used, it shall be drawn up in the official language of the issuing country and, in the case where the language used is neither English, French nor Spanish, the text of the certificate shall include a translation into one of these languages.

\section{2) Construction and equipment requirements}

The INF Code contains construction and equipment requirements which are more ship-specific such as damage stability, fire safety measures, temperature control of cargo spaces, etc. The more the total radioactive quantity is carried on board, the more stringent requirements are applied. In the case of Class INF 1 ships, the damage stability, fire safety measures and the electrical power supplies shall be to the satisfaction of its flag Administration. With regard to Class INF 2 ships, they

6) The review was for considering such issues as specific hazards related to maritime transport of flasks and consequences of severe accident scenarios, ship structural design requirements for securing flasks, the adequacy of existing requirements regarding marking, labelling and placarding of the flasks, route planning, notification to coastal States, restriction or exclusion of the ships from particularly sensitive sea areas, emergency preparedness and response, measures to locate and identify a sunken ship or lost flasks, monitoring the progress of the ship throughout the voyage by a shore based authority, etc. 
shall comply with the damage stability requirements in part $\mathrm{B}^{-1}$ of Chapter II- 1 of SOLAS, be fitted with various fire safety systems ${ }^{7)}$ in Chapter II-2 of SOLAS, and be provided with an alternative source of electrical power. For Class INF 3 ships, fire safety measures and the electrical power supplies are at the same level to those of Class INF 2 ships. However, regarding damage stability, more stringent requirements are applied for Class INF 3 ships; they shall comply with the damage stability requirements for type I ship survival capability and location of cargo spaces in the IBC Code or they shall comply with the damage stability requirements in part $\mathrm{B}^{-1}$ of Chapter II-1 of SOLAS, using more severe subdivision index as shown in the INF Code.

Other than the above, ventilation or refrigeration systems shall be provided for all Classes of INF ships in order to maintain average ambient temperature within cargo spaces not exceeding $55^{\circ} \mathrm{C}$ at any time. Furthermore, the other requirements related to construction and equipment, such as cargo securing arrangement, radiological protection measure, structural consideration for deck areas and support arrangements, are provided in the INF Code.

\section{3) Operational requirements}

Due to risks involved in ships carrying INF cargo, management of the ship and training of its crew would require more cautions. The INF Code provides that management and training related to INF ships shall be to the satisfaction of the flag Administration taking into consideration developments in IMO.

In addition, the Code contains the requirement regarding shipboard emergency plan. As previously mentioned, the requirement was introduced initially as an amendment to the recommendatory INF Code in 1997, urging that every ship carrying INF Code materials should carry a shipboard emergency plan approved by the flag Administration. The exact same requirements were reflected in the mandatory INF Code in 1999.

Furthermore, notification requirement which was introduced in 1997 as an amendment to the recommendatory INF Code was succeeded to the mandatory INF Code in 1999 for the purpose of the application of the reporting requirements of regulation $\mathrm{VII} / 7-1$ in SOLAS to the INF-related incident.

\section{Improvement of the INF Code}

Current regulatory regime is well established for the safe carriage of INF cargo. Requirements such as "IAEA Regulations for the Safe Transport of Radioactive Material" and "IMDG Code" secure the safety from the perspective of cargo. In addition, the current INF Code established by IMO may ensure the safety from the perspective of ships. However, considering the catastrophic results of potential accidents, it is necessary to continue identifying areas where improvement is required. The author is of the opinion that it is necessary to further enhance the international regulatory regime for sea transport of radioactive material by improving the INF Code. In addition, this improvement of the INF Code could be achieved by introducing additional measures such as enhancement of survey and certification scheme for INF ships, amendments to the INF Code and development of management and training guidelines as follows.

\subsection{Enhancement of survey and certification scheme under the INF Code}

In the Certificate of Fitness shown in Appendix of the INF Code, there is no section indicating its expiry date, which is different from the other certificates under SOLAS. This may lead to misunderstanding that it is a certificate which is permanently valid and consequently does not require periodical inspections. Although section 1.3.4 of the INF Code stipulates that the Certificate of Fitness shall cease to be valid when a certificate of that ship required by SOLAS has expired, it may be appropriate to indicate the expiry date directly on the Certificate of Fitness in order to prevent the aforementioned misunderstanding and facilitate monitoring its effectiveness regularly.

In addition, the INF Code section 1.3.3 requires that a ship certified for the carriage of INF cargo shall be subject to inspections and surveys under the applicable provisions of Chapter I of SOLAS in order to ensure that the structure, equipment, fittings, arrangements and material comply with the provisions of this Code. However, unlike from the other certificates under SOLAS, the form of the Certificate of Fitness does not have any endorsement section for periodical surveys. It may also cause attending surveyors to neglect or omit the periodical inspection in accordance with the INF Code requirements. If created, this

7) The systems include a water fire-extinguishing system, fixed fire-extinguishing arrangements in machinery spaces of category A, fixed cargo space cooling arrangements, a fixed fire-detection and fire alarm system. 
endorsement section will also facilitate monitoring its effectiveness regularly.

Furthermore, with regard to the regular check on the effectiveness of the Certificate of Fitness, the relevant survey guidelines would be useful. However, there are no survey guidelines for ships carrying INF cargo. Resolution A.1053(27) provides survey guidelines under the Harmonized System of Survey and Certification (HSSC). Especially, this also provides guidelines for carrying out periodical surveys for certain types of ships such as chemical tankers, gas carriers, etc. In the same context, it is necessary to develop survey guidelines for ships carrying INF cargo in order to facilitate the regular check on the effectiveness of the Certificate of Fitness. The fact that there are certain items which require special attentions specifically for ships carrying INF cargo will justify the development of these survey guidelines.

\subsection{Amendments to the INF Code to reflect updates to SOLAS references}

Some requirements in the INF Code are referring to provisions in SOLAS. Especially, due to the fact that the INF Code was adopted in 1999 before Chapter II-2 of SOLAS was completely revised by resolution MSC.99(73), requirements regarding fire safety measures in Chapter 3 of the Code are referring to provisions in the previous Chapter II-2 of SOLAS. However, it is necessary to update these references to SOLAS requirements for the purpose of proper application as shown in Table 1 . If some requirements in SOLAS are amended due to technical developments, it is necessary to amend the relevant requirements under the INF Code accordingly. More specifically, for example, the previous SOLAS regulation II-2/54.2.1.3, which is referred to under the INF Code section 3.2.3, requires the provision of means of effectively cooling the designated underdeck cargo space without specifying quantities of water. However, this requirement was updated as regulation II-2/19.3.1.3 in 2000 amendments to SOLAS where stated that means of effectively cooling the designated underdeck cargo space shall be provided with specific quantities of water. ${ }^{8)}$ In addition, engineering specifications for a fixed fire-detection and fire alarm system protecting the machinery spaces, accommodation and service spaces are continuously being developed. However, the INF Code section 3.2.4 is still referring to requirements in previous SOLAS regulation II-2/13 and this reference should be changed to FSS Code Chapter 9 which contains the latest specifications for the system. Furthermore, the INF Code sections 3.2.1 and 3.2.2 are referring to requirements for the water fire-extinguishing system and the fixed fire-extinguishing arrangement respectively in the previous SOLAS, which are not the latest ones

Table 1. Update of SOLAS references in the INF Code

\begin{tabular}{|c|l|c|c|}
\hline $\begin{array}{c}\text { INF Code } \\
\text { provisions }\end{array}$ & \multicolumn{1}{|c|}{ Requirements } & $\begin{array}{c}\text { SOLAS } \\
\text { references } \\
\text { (current) }\end{array}$ & $\begin{array}{c}\text { SOLAS } \\
\text { reference } \\
\text { to be updated }\end{array}$ \\
\hline 3.2 .1 & $\begin{array}{l}\text { A water } \\
\text { fire-extinguishing } \\
\text { system }\end{array}$ & $\begin{array}{c}\text { regulation } \\
\text { II-2/4 }\end{array}$ & $\underline{\underline{\text { regulation }}}$ \\
\hline 3.2 .2 & $\begin{array}{l}\text { Machinery spaces of } \\
\text { category A }\end{array}$ & $\begin{array}{c}\text { regulation } \\
\text { II-2/3.19 }\end{array}$ & $\underline{\underline{\text { regulation }}}$ \\
\hline 3.2 .2 & $\begin{array}{l}\text { Fixed }-2 / 3.31 \\
\text { fire-extinguishing } \\
\text { arrangements }\end{array}$ & $\begin{array}{c}\text { regulation } \\
\text { II-2/7 }\end{array}$ & $\underline{\underline{\text { regulation }}}$ \\
\hline 3.2 .3 & $\begin{array}{l}\text { Fixed cargo space } \\
\text { cooling arrangements }\end{array}$ & $\begin{array}{c}\text { regulation } \\
\text { II-2/54.2.1.3 }\end{array}$ & $\underline{\underline{\text { regulation }}}$ \\
\hline $3.2 / 19.3 .1 .3$ \\
\hline $\begin{array}{l}\text { A fixed fire-detection } \\
\text { and fire alarm } \\
\text { system, protecting the } \\
\text { machinery spaces, } \\
\text { accommodation and } \\
\text { service spaces }\end{array}$ & regulation & II-2/13 & $\underline{\underline{\text { FSS Code }}}$ \\
\hline
\end{tabular}

\subsection{Development of management and training guidelines}

According to Chapter 9 of the INF Code, management and training for a ship carrying INF cargo shall be to the satisfaction of the flag Administration. Furthermore, the Chapter is referring to guidelines which are to be developed by IMO. However, there are no such guidelines developed so far with regard to this. Although the Code was adopted in 1999, there has been no discussion within IMO regarding development of more specific guidelines for management and training for a ship carrying INF cargo. In the case of the Republic of Korea, Article 41-29) of Ship Safety Act provides requirements regarding education on safe transport of dangerous articles. However, there are no further specific requirements for ship's crews who are engaged in transportation of radioactive materials on board INF ships. This would be partly due to non-existence of the applicable international standards. Considering the risks involved in

8) At least 5 litres/min per square metre of the horizontal area of cargo spaces

9) Any person who is engaged in production, transportation, and loading of dangerous articles by a ship shall receive education provided by the Minister of Land, Transport and Maritime Affairs on safe transport of dangerous articles. 
ships carrying INF cargo and the importance of human element, it is essential to develop the specific guidelines for management of the ship and training of its crew.

\section{Conclusion}

Consequences of accidents related to ships carrying INF cargo could be catastrophic. Therefore, areas to be improved should be identified through continuous review. In this paper, it concludes that the current international regulatory regime related to sea transport of INF cargo should be further enhanced. In addition, measures for the purpose of the enhancement should be taken from the perspective of ship, that is, improvement of the INF Code.

As those measures, enhancement of survey and certification scheme under the INF Code, amendments to the INF Code to reflect updates to SOLAS references, and development of management and training guidelines were proposed in the above. The Republic of Korea is currently planning to submit the first two proposals to IMO MSC. If those proposals are approved by MSC after submission, the more detailed discussion would be held in Sub-Committee on Dangerous Goods, Solid Cargoes and Containers for amending the INF Code whereas Sub-Committee on Flag State Implementation would develop detailed items of survey guidelines for INF ships. With regard to the last proposal to develop the specific guidelines for management of the ship and training of crew, it is necessary to investigate further the actual practices of the relevant flag States in order to make the concrete proposal to IMO, which should be dealt with through the future study.

\section{Acknowledgements}

This study was carried out as a part of "Project regarding Strategic Response to IMO Meetings" supported by Ministry of Land, Transport and Maritime Affairs in 2012.

\section{References}

[1] Booker, P. A.(2003), "Development of the INF Code and its relationship to the Ships of the Pacific Nuclear Transport Fleet", Proceedings in IAEA International Conference on the Safety of Transport of Radioactive Material, Vienna, pp. 1-4.

[2] IAEA(2001), Severity, probability and risk of accidents during maritime transport of radioactive material
(IAEA-TECDOC-1231), p. 1.

[3] IAEA(2005), Regulations for the Safe Transport of Radioactive Material 2005 Edition, pp. 1-2.

[4] IMO(1993), Code for the Safe Carriage of Irradiated Nuclear Fuel, Plutonium and High-Level Radioactive Wastes in Flasks on Board Ships(Resolution A.748(18)), Annex, pp. 1-4.

[5] IMO(1995), Review of the Code for the Safe Carriage of Irradiated Nuclear Fuel, Plutonium and High-Level Radioactive Wastes in Flasks on Board Ships(Resolution A. 790(19)), pp. 1-2.

[6] IMO (1996), Focus on IMO: IMO and dangerous goods at sea, pp. 5-7.

[7] IMO(1997a), Amendments to the Code for the Safe Carriage of Irradiated Nuclear Fuel, Plutonium and High-Level Radioactive Wastes in Flasks on Board Ships(Resolution A. 853(20)), Annex, pp. 1-3.

[8] IMO(1997b), Guidelines for Developing Shipboard Emergency Plans for Ships Carrying Materials Subject to the INF Code(Resolution A.854(20)), p. 1.

[9] IMO(1999a), Adoption of Amendments to the International Convention for the Safety of Life at Sea, 1974, as Amended(Resolution MSC 87(71)), Annex, pp. $1-2$.

[10] IMO(1999b), Adoption of the International Code for the Safe Carriage of Irradiated Nuclear Fuel, Plutonium and High-Level Radioactive Wastes on Board Ships(Resolution MSC 88(71)), Annex, pp. 1-8.

[11] Kim, D. S.(2009), International Law, 14th ed., Seoul: Samyoungsa, p. 1118.

[12] Kim, H. K.(2010), International Environmental Law, Seoul: Hongmoonsa, p. 61.

[13] Roe, M. J.(2003), New International Environmental Law, Seoul: Bobmunsa, p. 74.

[14] WNTI(World Nuclear Transport Institute)(2006), Radioactive Materials Transport The International Safety Regime: An Overview of Safety Regulations and Organisations Responsible for their Development, WNTI Review Series No. 1, pp. 65-76.

[15] Wonham, J. et al.(2000), "Marine transportation of irradicated nuclear fuel, plutonium and radioactive wastes: the continuing debate on regulatory measures", Marine Policy, Vol. 24, pp. 287-299.

Received 24 August 2012

Revised 19 September 2012

Accepted 21 September 2012 